Article

\title{
How Does Technological and Financial Literacy Influence SME Performance: Mediating Role of ERM Practices
}

\author{
K.M.M.C.B. Kulathunga ${ }^{1,2, * \mathbb{D}}$, Jianmu Ye ${ }^{1, *}$, Saurabh Sharma ${ }^{1} \mathbb{D}$ and P.R. Weerathunga ${ }^{1}$ (D) \\ 1 School of Management, Wuhan University of Technology, Wuhan 430070, China; \\ sharma.saurabh02@gmail.com (S.S.); weerathungaroshan@gmail.com (P.R.W.) \\ 2 Department of Management Sciences, Faculty of Management, Uva Wellassa University of Sri Lanka, \\ Badulla 90000, Sri Lanka \\ * $\quad$ Correspondence: maduranga@uwu.ac.lk (K.M.M.C.B.K.); jianmuye@whut.edu.cn (J.Y.)
}

Received: 30 April 2020; Accepted: 27 May 2020; Published: 1 June 2020

\begin{abstract}
The knowledge-based view (KBV) in the development of small and medium-sized enterprises (SMEs) is a debatable topic in the current literature. Although convergence of technological and financial literacy (techno-finance literacy) is an essential knowledge-based tool to address rapid digitalization of business, the influence of techno-finance literacy in the development of SMEs is still not adequately researched. Drawing upon KBV, we developed a single-mediator structural model with an aim to explore the effect of techno-finance literacy and enterprise risk management (ERM) practices (applications) on the performance of SMEs. A self-administered structured questionnaire was employed to collect data from 319 chief financial offers (CFOs) in Sri Lankan SMEs. The outcome of our study highlights that techno-finance literacy is a significant determinant of two endogenous constructs, namely, SME performance and ERM practices. Furthermore, ERM practices of SMEs were also positively affected to the SME performance. Moreover, ERM practices were observed to have a partial mediation on the relationship between financial literacy and SME performance. These findings form the basis for theories in techno-finance literacy and SME performance, as well as present managerial implications to enhance the performance of SMEs.
\end{abstract}

Keywords: technological literacy; financial literacy; SME performance; ERM practices

\section{Introduction}

Small and medium-sized enterprises (SMEs) play a significant role in the economic development of a country, and their contributions are well established in the literature [1,2]. A well-developed SME sector is essential to the steadiness of industrial environment, thereby contributing to consistent and steady economic growth [3]. Despite the contribution of SMEs in economic development, research demonstrated that the performance of SMEs is lower in developing nations, preventing them from contributing their quota effectively in the development of the economy [4,5]. In general, shortage of capital and credit facilities, absence of skilled workers, lack of raw materials, poor infrastructure, shortage of workforce having necessary management skills, and the contained use of new, emerging, and constantly changing technologies were observed as the barriers for SME performance [6,7]. Therefore, there is a pressing need for exploring factors and mechanisms that can contribute in facilitating SME performance, especially in emerging markets.

With growing recognition of the importance of knowledge resources in organizational performance, knowledge-based view (KBV) is gaining prominence. KBV essentially proposes ways to enhance the performance of organizations [8]. For instance, KBV emphasized the value and necessity of integrating both individual- and firm-level knowledge into organizational products and services 
to gain competitive advantages in this complex business environment [9]. With the interaction of $\mathrm{KBV}$, researchers and practitioners identified a vast number of dynamic knowledge resources that can influence organizational performance [10-12]. However, many of those studies focused on large-scale organizations, while little attention was devoted toward SME performance [13]. Thus, it is challenging for SMEs to emphasize on the most appropriate knowledge-based resources to enhance their performance. In this study, our goal is to investigate two possible knowledge-based resources, namely, technological literacy and financial literacy (techno-finance literacy), and their relevance in SME performance.

The emergence of new technology and digital information revolutionized the global business environment $[5,14,15]$. Even though this technological revolution strengthens the business environment, it also creates more risks and challenges for the survival of business. Therefore, to manage volatile market conditions that arise with technological revolution, business organizations need knowledge that is more specific. Accordingly, technological literacy can be determined as a crucial knowledge resource, which can assist in gaining advantages emerging from the technological revolution. Meanwhile, technological literacy is an important antecedent that influences the technological adoption [16-18]. With regard to SMEs, technological literacy can be highlighted as a crucial knowledge resource which assists them to expand their business across the globe $[19,20]$. However, SMEs in developing countries are still behind the curve on technological transition, and they are witnessing disruptive effects in their performance [21]. Despite the importance of technological literacy in SME performance, adoption and usage of technology can only be significant if the firm has relevant, as well as enough, knowledge to use these technologies.

Similarly, financial literacy is among the important knowledge resources that elevate the individual's and firm's capacity, skills, and expertise to use technology effectively. Furthermore, financial literacy and technological literacy are often mutually supportive at the individual and corporate level. Therefore, integration of technological and financial literacy is important for improving organizational performance. Moreover, not much focus was given on the intersection of particular knowledge resources like technological literacy and financial literacy, and the area lacks thorough research on how they mutually influence the performance of SMEs [15]. Therefore, this study stipulates a detailed analysis of techno-finance literacy and investigates the pathways through which techno-finance literacy can enhance SME performance, thereby extending the literature on the issue.

This research contributes to the techno-finance literacy and SME performance literature in five ways. Firstly, this study used KBV to emphasize the prominence of techno-finance literacy and enterprise risk management (ERM) in SME performance by following and extending the contemporary work of eminent scholars [3,6]. Secondly, this research extends the awareness of ERM, as it examines ERM's position as a mediator in the relationship between techno-finance literacy and performance of the SMEs. It also extends the literature by using partial least structural equation modeling (PLS-SEM) in the context of techno-finance literacy. Thirdly, even when techno-finance literacy was recognized as a crucial determinant in SMEs performance, its combined effect was less investigated, especially in developing countries [13]. This study investigates the combined effect of techno-finance literacy on SME performance in Sri Lanka, bridging this contextual gap. Fourthly, the conceptual framework developed in this research could be a vital tool to intensify the performance of the SME sector. Fifthly, the findings of this study could enable managers and policymakers to develop policies, programs, and strategies in order to ensure SME performance.

The rest of this paper is structured as follows: Section 2 provides a brief discussion on the relevant literature and hypotheses of the study. Section 3 describes our research methodology, including population and sample, data collection procedures, measurement scales of variables, and data analysis methods used. The results and discussion on the findings of the study are summarized in Section 4 . Section 5 outlines the theoretical and management implications, research limitations, and future research avenues; lastly, conclusions are presented in the final section of our paper. 


\section{Literature Review and Hypothesis Development}

The knowledge-based view (KBV) is an organizational learning management concept that provides companies with strategies to realize a competitive advantage $[8,22]$. Competitive advantages are achieved through increased involvement of employees in formulating and managing the company's operational goals and long-term transformation goals [23]. Continuous knowledge acquisition and transfer within business organizations are demanded by dynamics such as regularly changing economic conditions in globalization-initiated markets, privatization, and technological advances.

$\mathrm{KBV}$ is an essential organizational learning methodology that contributes to improvements in the knowledge resources of the organizations [24]. KBV suggests setting up heterogeneous knowledge systems across a company's management hierarchies as a tactic to get competitive advantages based on sustainable knowledge. This is because knowledge-based tools are always characterized by difficulties such as distribution, imitation, and social complexities [25]. Technological business applications were identified as an essential tool for developing knowledge capabilities [26]. Organizations are rapidly embracing new technologies for the execution of transactions, management of customer relationships, asset management, and total quality management, as well as improving skills and creativity among the workforce. Organizations can use sophisticated technologies to create a collaborative work atmosphere by providing workers with the ability to share information through online communication methods such as forums, emails, discussion groups, intranets, and video conferencing. Thus, knowledge can be recognized as a strategic resource for managing the organization's competitive advantage by adding value to business data, information processes, and operational systems [27].

Explicit knowledge and implicit knowledge are the two main types of knowledge that businesses can find in their search for a competitive advantage. Explicit knowledge is the comprehensive knowledge that can be identified with organizational processes, documents, and information systems of the company, which is easy to articulate and understand [28]. Explicit knowledge is commonly used by competing firms in order to sustain a competitive advantage as a reaction to changes in market conditions. Companies use tacit knowledge to get advantage of a person or company-specific skills that are difficult to communicate or encapsulate in competitive terms. Curado and Henriques [29] agree that the intangible and complex essence of tacit knowledge generates the necessity of an idiosyncratic approach to organizational development. Organizations apply tacit knowledge as they respond to dynamics in the business environment (such as business digitalization) or industry regulatory changes that open up the market to competitors [30]. The improvement of organizational tacit knowledge is heavily dependent on employees' knowledge-sharing ability and their enthusiasm to pursue education and research beyond the company's borders.

KBV provides the theoretical background for this study. Accordingly, financial literacy and technological literacy can be identified as intangible resources, which determine SME performance. Moreover, these resources are also difficult to imitate and transfer, as well as embed in the organization. Moreover, these skills and the expertise knowledge create competitive advantages, in turn enhancing the organizational performance. The ability of value creation through knowledge-based resources is essential to uplift organizational performances [30]. In this sense, techno-finance literacy is deemed to be a vital knowledge resource in organizational value creation [31,32]. Techno-finance knowledge strengthens the competence of an organization, which eases the flexibility to adopt environmental changes while extracting profitable opportunities. Moreover, intellectual capital positively affects organizational performances [33]. Accordingly, business firms should understand the importance of techno-finance literacy in order to enhance the organizational performance.

\subsection{Technological Literacy and SME Performance}

Technological literacy is a vital and powerful tool to ensure organizational performance in a digitalized business environment [34-36]. Furthermore, technological literacy enhances the organizational decision-making process through efficient information management. Accordingly, technology literacy enables SMEs to collect, evaluate, interpret, and share relevant and timely information efficiently [37,38]. 
Meanwhile, Ladokun and Osunwole [39] identified the significance of technological literacy to improve organizational business processes. Technological literacy is also important in organizational planning, interaction and cooperation, consumer service, and business administration [40]. Ashrafi and Murtaza [41] and Iansiti and Lakhani [42] also highlighted a positive relationship between technological literacy and SME performance. Consequently, in this digitalized economy, it is necessary to understand the prominence and strategic role of technological literacy to enhance SME performance.

Despite the importance of technology in the development of SMEs, the adoption of technology by SMEs remains low [18]. However, the significant contribution of modern technology to SME performance cannot be underestimated. For instance, China, India, the United Kingdom (UK), and the United States (US) took the full benefits of the knowledge economy through increased technological literacy to develop their countries, particularly the SME sector. Researchers also identified technological literacy as a key driving force in SME sustainable performance [43-45]. However, most SMEs have failed to acquire sophisticated technology due to cash flow problems, thereby stagnating their development [46-48]. Even though, in this digitalized business world, financing strategies such as crowd financing are available to SMEs to mitigate the financial risks, low technological literacy can hinder those opportunities $[15,49]$. Therefore, in this digitalized business environment, SMEs should be technically qualified in order to enhance their performance [50]. Accordingly, we hypothesize the following:

Hypothesis 1. Technological literacy is positively related to SME performance.

\subsection{Financial Literacy and SME Performance}

The resource-based view (RBV) emphasized the prominence of tangible and intangible assets in generating competitive advantages for organizations, thereby improving their performance [51]. Conner and Prahalad [52] stressed the need for a broad variety of resources, particularly knowledge resources, in order to sustain the competitive advantages. Researchers also highlighted the positive association between intellectual capital and the performance of organizations [53]. Consequently, financial literacy is also deemed to be a powerful intellectual capital in SME performance. Financial literacy would enable and enhance the performance of SMEs in this complicated business environment by strengthening the knowledge base of organizations [31,54]. Moreover, financial literacy contributes to the organizational decision process and, hence, helps organizations to adapt to changes and exploit the opportunities that these changes offer [8]. Therefore, improved knowledge on financial literacy is indeed very significant and imperative to SME performance.

Researchers observed financial literacy having a positive influence on SME performance [55]. Financial literacy facilitates managers to pinpoint financial aspects in business decisions, thereby increasing their performance. Furthermore, financial literacy significantly affects SME performance in both developed and developing countries [56]. Most financial mistakes are triggered due to poor financial literacy [54]. Huston [55] highlighted the important role of higher financial literacy to deal with on-going economic transitions. Similarly, Widdowson and Hailwood [57] noted the necessity of higher financial literacy to make efficient investments. Davidson III and Xie [58] also revealed the positive impact of financial literacy on firm performance. Along with that, Behrman and Mitchell [59] identified the prominent role of financial literacy in organizational wealth accumulation. Accordingly, financial literacy was recognized as a leading force in managerial decision-making [60], as well as in strategic, sustainable financial planning [54]. Therefore, it is believed that higher financial literacy significantly influences SME performance. Hence, we hypothesize the following:

Hypothesis 2. Financial literacy is positively related to SME performance. 


\subsection{Enterprise Risk Management Practices and SME Performance}

The significance of ERM practices is evolving more than ever with rapid changes occurring in the modern business environment [61,62]. In order to develop and introduce strong ERM practices for SMEs, it becomes vital to comprehend the determinants and the role of sound ERM practices in SME performance. Strong ERM practices can influence SME performance in many ways. For instance, operational cost reduction, effective utilization of organizational assets, control of financial fraud, and efficient information management are some of the advantages of strong ERM practices [63]. Along with these, effective ERM practices allow managers to foresee the opportunities and challenges evolving with global economic changes and aid them in developing appropriate long-term plans and strategies to enhance organizational performance [61]. Moreover, competitive advantages that arise because of implementing efficient ERM practices also allow organizations to manage their financial and business risks and, in turn, improve their organizational performance $[10,64,65]$. Accordingly, organizations with strong ERM practices perform well compared to other organizations [66,67]. Managers, therefore, are emphatically recommended and impelled to implement strong ERM practices to enhance SME performance $[68,69]$. Overall, it can be assumed that a positive relationship exists between ERM practices and SME performance. Therefore, the following hypothesis is proposed:

Hypothesis 3. ERM practices are positively related to SME performance.

\subsection{The Links between Technological Literacy, ERM Practices, and SME Performance}

The relationship between technological literacy and SME performance via ERM practices can be explained with the evolutionary theory of economic changes. This theory emphasized the requirement of searching for innovative solutions to enhance the performance of business organizations [70]. Furthermore, the evolutionary theory of economic changes underlines the requirement of identifying new variables, which contributes to successfully dealing with this competitive business climate. In this study, we used this theory to explain the importance of technological literacy in SME performance. In this digitalized business environment, technological literacy empowers managers to navigate the global economy and to identify innovative solutions to financial and business matters [71,72]. Accordingly, technological literacy expands the scope of knowledge, as well as promotes the acquisition of skills and innovativeness of top management and, thus, enhances SME performance. Moreover, improved knowledge and skill with regard to technology will contribute to the implementation of a strong internal control system, particularly ERM practices that will promote the performance of SMEs.

Technological literacy can contribute to SME performance in different manners. Generally, SMEs respond to technological changes in different ways. For instance, SMEs having low technological literacy rely on traditional strategies, while SMEs with high technological literacy put in use that knowledge to deal with the technological changes [73]. Furthermore, technological literacy also influences SME policy decisions that, in turn, could affect their ERM practices [74]. From this viewpoint, we suggest that the relationship between technological literacy and SME performance can be mediated by some internal factors like ERM practices. Sound ERM practices would be vital in organizational decision-making especially in long-term planning and strategy implementation. Higher technological literacy enables managers to develop and implement sophisticated organizational ERM systems and has a positive influence on strategic decision-making, cost reduction, and operations of organizations, thereby contributing to SME performance [75]. Accordingly, we hypothesize that ERM practices represent a significant mediator between technological literacy and SME performance. Hence, we propose the following hypotheses:

Hypothesis 4. Technological literacy has a positive effect on ERM practices.

Hypothesis 5. ERM practices mediate the relationship between SME technological literacy and performance. 


\subsection{The Links between Financial Literacy, ERM Practices, and SME Performance}

Researchers devoted only scant attention to the relationship between financial literacy and ERM practices. However, the effectiveness of an ERM system depends on the financial literacy of the organization [76]. Higher financial literacy allows managers to foresee the economic changes and to identify the risks involved with those changes. Therefore, it is essential to have a higher financial literacy to link organizational strategies, cost strategies, accounting practices, and policies and procedures with the ERM system [77]. Furthermore, the involvement of top management is indeed important to design strong ERM practices for organizations. Moreover, Shanahan and McParlane [78] stressed the significance of financial literacy in developing organizational strategies and risk management practices. Thus, we argue that a manager's financial literacy can influence the ERM practices of SMEs.

Financial literacy is a major determinant in the development of SMEs. Yet, financial literacy itself does not always enhance organization performance. The indirect influential mechanism of financial literacy via ERM practices on the performance of SMEs can be elucidated with KBV. SMEs require certain knowledge to understand and evaluate financial and business risks in order to develop and implement effective ERM practices [77]. According to the KBV, both explicit and tacit knowledge are useful in developing sound ERM practices. For instance, organizations can use explicit knowledge to identify industry trends, while tacit knowledge is essential to respond to the changes in business environments, such as business digitalization [30]. Thus, knowledge can be identified as a strategic resource which helps to maintain the organization's competitive advantage by adding value to business data, information processes, and operational systems [27]. Accordingly, prevalence of higher financial knowledge would help managers to develop strong ERM practices for SMEs and enhance their performance. Consequently, managers having higher financial literacy are able to bring down risks by adopting strong risk management practices, resulting in enhancing SME performance $[79,80]$. Thus, the indirect effect of the financial literacy, through sound ERM practices, leads to SME performance. Hence, we propose the following hypotheses:

Hypothesis 6. Financial literacy has a positive effect on ERM practices.

Hypothesis 7. ERM practices mediate the relationship between financial literacy and SME performance.

The hypothesized relationships and the variables are shown in Figure 1.

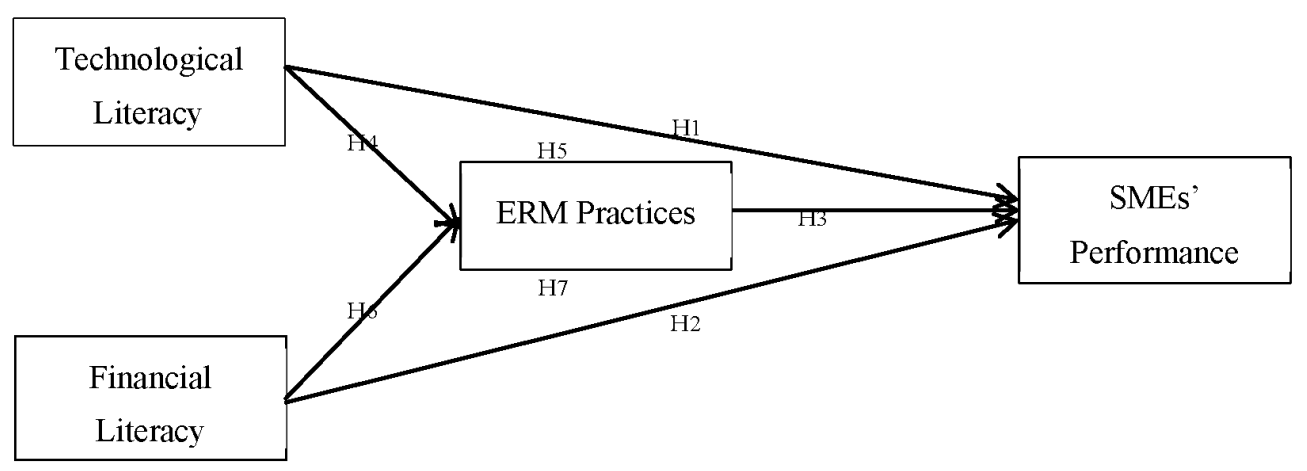

Figure 1. Conceptual framework.

\section{Methodology}

\subsection{Sample Design and Data Collection}

All the SMEs in Sri Lanka were taken as the population of this study. In this research, we used the definition provided by the World Bank to identify SMEs. Accordingly, organizations that had 5-99 employees were identified as SMEs. The final sample consisted of 325 SMEs, located in Central, Western, and Southern provinces of Sri Lanka. In Sri Lanka, more than $60 \%$ of SMEs are located in these three provinces, contributing $60 \%$ to the national gross domestic product (GDP) of the country. 
Considering the contribution to national GDP from each province, we selected 215 SMEs from the Western province, 54 SMEs from the Central province, and 56 SMEs from the Southern province. Due to the lack of a comprehensive database on SMEs in Sri Lanka, we used the Yellow Pages directory which consisted of the industry sector and contact details of organizations to identify a sample framework for this study. Firstly, we had telephonic conversations with the CFO of each SME and requested information on the number of employees. If the number of employees was between five and 99, we requested them to be a part of our study and arranged a visit to their organization to collect data.

In this research, we employed structured questionnaire to collect data. Questionnaire surveys allow examining the views of a large number of people who are geographically scattered. Furthermore, a questionnaire survey is an effective way of gathering information when an attitude, perception, or belief is the subject of interest [81]. It is also the most straightforward approach to investigating the information needs of users.

The questionnaire was piloted with 20 participants who have managerial experience. According to Burns and Bush [82], a pilot study between 15 and 30 representative participants is adequate to find flaws in a questionnaire. Participants received questionnaires by hand and were asked to complete and give feedback on the content of the questionnaire. They were asked to identify unanticipated errors such as awkward expressions, unclear concepts, double questions, missing alternatives, and leading questions, as well as to indicate the time required by the respondent to complete the questionnaire. In response to the pilot study, some items of the scale were revised and rewritten. The pilot study also led to the elimination of two items on financial literacy. Accordingly, there were 30 items in the final version of the questionnaire representing four perspectives. It took an average of about 20 minutes to complete the survey. Finally, we collected data from 325 SMEs. A total of six questionnaires were found invalid due to missing data on key variables and, therefore, the final sample for analysis comprised 319 usable surveys. This represents an effective response rate of $98 \%$. Hence, the response rate of the present research is highly acceptable.

The profile of the sample was as follows: when considering the industry sector, the highest percentage $(41.1 \%)$ of firms were from the manufacturing sector, while $29.2 \%$ and $29.7 \%$ of firms represented the service and trade sectors, respectively. When considering the number of employees, $28.8 \%$ of firms had $21-40$ employees and $27 \%$ of firms had $41-60$ employees. Furthermore, $17.2 \%$ had 61-80 employees, while $16.6 \%$ had 5-20 employees and 10.4\% had $81-99$ employees. Almost 30\% of SMEs were operating for 6-15 years, while $28.9 \%$ of SMEs were established for $16-25$ years. On the other hand, $22.9 \%$ of the SMEs were newly established firms, while $17.8 \%$ of SMEs operated over 26 years (see Table 1 ).

Table 1. Profile of the sample.

\begin{tabular}{lcc}
\hline & Frequency & Percentage \\
\hline Industrial sector & & \\
\hline Manufacturing & 131 & $41.1 \%$ \\
Service & 93 & $29.2 \%$ \\
Trade & 95 & $29.7 \%$ \\
\hline Size & & \\
\hline 5-20 employees & 53 & $16.6 \%$ \\
$21-40$ employees & 92 & $28.8 \%$ \\
$41-60$ employees & 86 & $27.0 \%$ \\
$61-80$ employees & 55 & $17.2 \%$ \\
$81-99$ employees & 33 & $10.4 \%$ \\
\hline Age & & \\
\hline <5 years & 73 & $22.9 \%$ \\
$6-15$ years & 97 & $30.4 \%$ \\
$16-25$ years & 92 & $28.9 \%$ \\
$\geq 26$ years & 57 & $17.8 \%$ \\
\hline
\end{tabular}




\subsection{Measurement of Variables}

To achieve the objectives of our study, we used four variables, which were measured using items adapted from past studies. All items were modified so as to suit the Sri Lankan context and were measured using a seven-point Likert scale, ranging from 1 (strongly disagree) to 7 (strongly agree).

Technological Literacy: To measure technological literacy, we adopted the scale described by Pham [83]. Originally, this measurement scale was developed to measure information and communications technology (ICT) maturity of SMEs. A total of five items were used to measure the technological literacy of SMEs after changing it as per the needs of Sri Lankan context. Sample items included "we use computerized accounting software to prepare financial reports" and "we use online banking system to do our banking activities".

Financial Literacy: Previous researches used the knowledge on macro-economic variables such as interest rates, exchange rates, inflation, and time value of money as proxies of financial literacy [13]. Due to the importance of financial management practices for SMEs to survive in this modern digitalized business environment, in this study, we looked for a more practical measurement scale to index the SMEs financial literacy. Therefore, the measurement scale developed by Bongomin and Munene [84] was used to measure CFO financial literacy in our sample of SMEs. This scale consisted of 13 items such as "we have the ability to analyze the firm's financial performance periodically" and "my firm prepares monthly income statements".

Enterprise Risk Management Practices: Different scholars used various proxies to measure ERM practices. In this study, we were supposed to use key dimensions of risk in order to measure ERM practices of SMEs. Therefore, in this study, we employed the measurement scale used by Sax and Torp [85] to measure ERM practices of our sample of SMEs. This scale consisted of six items, with sample items such as "we have standard procedures in place for launching risk-reducing measures" and "we regularly prepare risk reports for the top management and the board of directors".

SME Performance: Even though previous studies used financial data as a proxy to measure organizational performance, in the SME context, it is challenging to find financial data [86] due to many reasons such as entrepreneur reluctance to provide finance-related data to a third party [87] and the difficulty of verifying the accuracy of available financial data [88]. However, it is recommended to use self-reported data when it is difficult to find objective data in social science researches. Accordingly, we measured SME performance using the CFO's assessment of the firm performance by using the measurement scale developed by Degong and Ullah [89]. This scale had eight items, and we asked CFOs to assess their firm's performance compared to their competitors. Sample items included "reducing operating costs" and "increasing customer satisfaction".

\section{Results}

\subsection{Measurement Model Assessment}

The measurement model had four, first-order reflective constructs. Initially, we evaluated the measurement model to confirm the suitability of selected constructs to carry out this study. Accordingly, the content validity was checked through three methods. Firstly, all the constructs in this research were identified through a robust literature review. Secondly, several industry experts and academics in the fields of management, finance, and research methodology were consulted by the researchers to determine the validity of the content. Thirdly, the measure was pilot-tested with 20 individuals with managerial experience. However, slight modifications were made to the questionnaire before the final distribution.

Normality of the data was checked using skewness and kurtosis values. Table 2 depicts the absence of a normality issue for the data, as all the skewness and kurtosis values were between -1 and +1 [90]. Two items were removed (one each from financial literacy and SME performance) because of the poor indicator outer loadings $(<0.4)$, which resulted in an increase of construct reliability and validity [90]. Table 2 summarizes the reliability, validity, and descriptive statistics of the constructs. 
Table 2. Reliability, validity, and descriptive statistics of the constructs. VIF-variance inflation factor; ERM—enterprise risk management; SME—small and medium-sized enterprise.

\begin{tabular}{|c|c|c|c|c|c|c|c|}
\hline Construct & Items & Loading & Mean & SD & Skewness & Kurtosis & VIF \\
\hline \multirow{5}{*}{$\begin{array}{c}\text { Technological } \\
\text { Literacy }\end{array}$} & TL1 & 0.870 & 4.7000 & 1.65450 & -0.572 & -0.344 & 2.127 \\
\hline & TL2 & 0.852 & 4.3200 & 1.85254 & -0.463 & -0.817 & 1.684 \\
\hline & TL3 & 0.810 & 4.5900 & 1.86458 & -0.306 & -0.931 & 2.451 \\
\hline & TL4 & 0.794 & 3.8000 & 1.28708 & -0.748 & -0.588 & 2.583 \\
\hline & TL5 & 0.847 & 4.4200 & 1.80448 & -0.526 & -0.742 & 2.043 \\
\hline \multirow{10}{*}{$\begin{array}{l}\text { Financial } \\
\text { Literacy }\end{array}$} & FL1 & 0.732 & 4.0700 & 1.45821 & 0.295 & -0.416 & 1.841 \\
\hline & FL2 & 0.757 & 4.8800 & 1.47901 & -0.114 & -0.951 & 2.582 \\
\hline & FL3 & 0.652 & 4.4500 & 1.51341 & -0.054 & -0.441 & 2.947 \\
\hline & FL4 & 0.757 & 4.0900 & 1.54459 & 0.165 & -0.513 & 2.164 \\
\hline & FL5 & 0.787 & 4.2300 & 1.58181 & -0.029 & -0.576 & 1.973 \\
\hline & FL6 & 0.765 & 5.0200 & 1.50407 & -0.507 & -0.583 & 1.473 \\
\hline & FL7 & 0.707 & 4.6500 & 1.56589 & -0.365 & -0.557 & 1.639 \\
\hline & FL8 & 0.771 & 4.8300 & 1.57669 & -0.171 & -0.882 & 2.078 \\
\hline & FL9 & 0.769 & 4.4100 & 1.62739 & -0.202 & -0.660 & 2.665 \\
\hline & FL10 & 0.804 & 4.9800 & 1.53070 & -0.518 & -0.464 & 1.943 \\
\hline \multirow{6}{*}{ ERM } & ERM1 & 0.832 & 4.8500 & 1.43108 & -0.385 & -0.442 & 2.845 \\
\hline & ERM2 & 0.735 & 5.5100 & 1.32188 & -0.531 & -0.658 & 1.869 \\
\hline & ERM3 & 0.738 & 5.2000 & 1.50420 & -0.894 & 0.433 & 2.537 \\
\hline & ERM4 & 0.807 & 4.9500 & 1.55294 & -0.724 & 0.322 & 2.664 \\
\hline & ERM5 & 0.740 & 4.5900 & 1.45710 & -0.172 & -0.866 & 2.476 \\
\hline & ERM6 & 0.812 & 4.9900 & 1.54066 & -0.693 & -0.013 & 1.872 \\
\hline \multirow{7}{*}{$\begin{array}{c}\text { SME } \\
\text { Performance }\end{array}$} & FP1 & 0.817 & 4.5900 & 1.29564 & -0.870 & 0.912 & 2.493 \\
\hline & FP2 & 0.845 & 4.9100 & 1.44875 & -0.684 & 0.343 & 2.055 \\
\hline & FP3 & 0.854 & 5.0500 & 1.50000 & -0.756 & 0.255 & 1.846 \\
\hline & FP5 & 0.755 & 3.1100 & 1.17975 & -0.330 & -0.854 & 2.460 \\
\hline & FP6 & 0.782 & 4.6400 & 1.22697 & -0.984 & 0.858 & 2.573 \\
\hline & FP7 & 0.796 & 4.5365 & 1.26953 & -0.921 & 0.898 & 2.417 \\
\hline & FP8 & 0.784 & 3.9700 & 1.15168 & -0.469 & -0.866 & 2.835 \\
\hline
\end{tabular}

As recommended by Hair Jr and Hult [90], Cronbach's alpha and composite reliability (CR) were used to assess the reliability and internal consistency; while following the recommendations [91], we used average variance extracted (AVE) values and outer loading (see Table 2) to evaluate the convergent validity. Results are summarized in Table 3. Accordingly, all the Cronbach's alpha values and $C R$ values were higher than the threshold of 0.7 , while AVE was higher than 0.5 , thus providing evidence for the reliability, internal consistency, and convergent validity of the dataset.

Table 3. Internal consistency reliability and convergent validity. CR-composite reliability; AVE-average variance extracted.

\begin{tabular}{cccc}
\hline Latent Variable & Cronbach's Alpha & CR & AVE \\
\hline Technological Literacy & 0.893 & 0.870 & 0.697 \\
Financial Literacy & 0.914 & 0.891 & 0.564 \\
ERM Practices & 0.870 & 0.863 & 0.606 \\
SME Performance & 0.911 & 0.890 & 0.649 \\
\hline
\end{tabular}

The Fornell and Larcker [91] criterion and Heterotrait-Monotrait ratio (HTMT) [92] were used in order to assess the discriminant validity of the data. Results for the Fornell and Larcker [91] criterion are summarized in the Table 4, and bold values on the diagonal of the correlation matrix are the square root of the AVE, which were higher than the latent variable correlations, thus providing evidence for the accuracy of the discriminant validity. Furthermore, HTMT values for all latent variables were below 0.9 , which also provided evidence for the accuracy of the discriminant validity (see Table 5). 
Table 4. Discriminant validity-Fornell and Larcker criterion.

\begin{tabular}{ccccc}
\hline Variable & TL & FL & ERM & FP \\
\hline Technological Literacy (TL) & $\mathbf{0 . 8 3 4}$ & & & \\
Financial Literacy (FL) & 0.527 & $\mathbf{0 . 7 5 1}$ & & \\
ERM Practices (ERM) & 0.495 & 0.474 & $\mathbf{0 . 7 7 8}$ & \\
SME Performance (FP) & 0.416 & 0.504 & 0.613 & $\mathbf{0 . 8 0 5}$ \\
\hline
\end{tabular}

Notes: Bold values on the diagonal of the correlation matrix are the square root of AVE.

Table 5. Discriminant validity-Heterotrait-Monotrait ratio.

\begin{tabular}{ccccc}
\hline Variable & TL & FL & ERM & FP \\
\hline Technological Literacy & - & & & \\
Financial Literacy & 0.803 & - & & \\
ERM Practices & 0.793 & 0.784 & - & \\
SME Performance & 0.779 & 0.813 & 0.726 & - \\
\hline
\end{tabular}

\subsection{Structural Model Evaluation and Testing the Hypotheses}

As the first step of structural model evaluation, we conducted a multicollinearity assessment [90] using the variance inflation factors (VIFs). In this study, all the VIF values were below the threshold of 3, indicating the absence of multicollinearity in the data (see Table 2). Next, we assessed the significance of the path coefficients using the bootstrapping approach suggested by Hair Jr and Hult [90]. Accordingly, we used 5000 subsamples and assessed the significance of path coefficients using the cut-off value of 1.96 (5\% significance). Results show that all path coefficients were statistically significant and supported all direct hypotheses of this study (Figure 2).

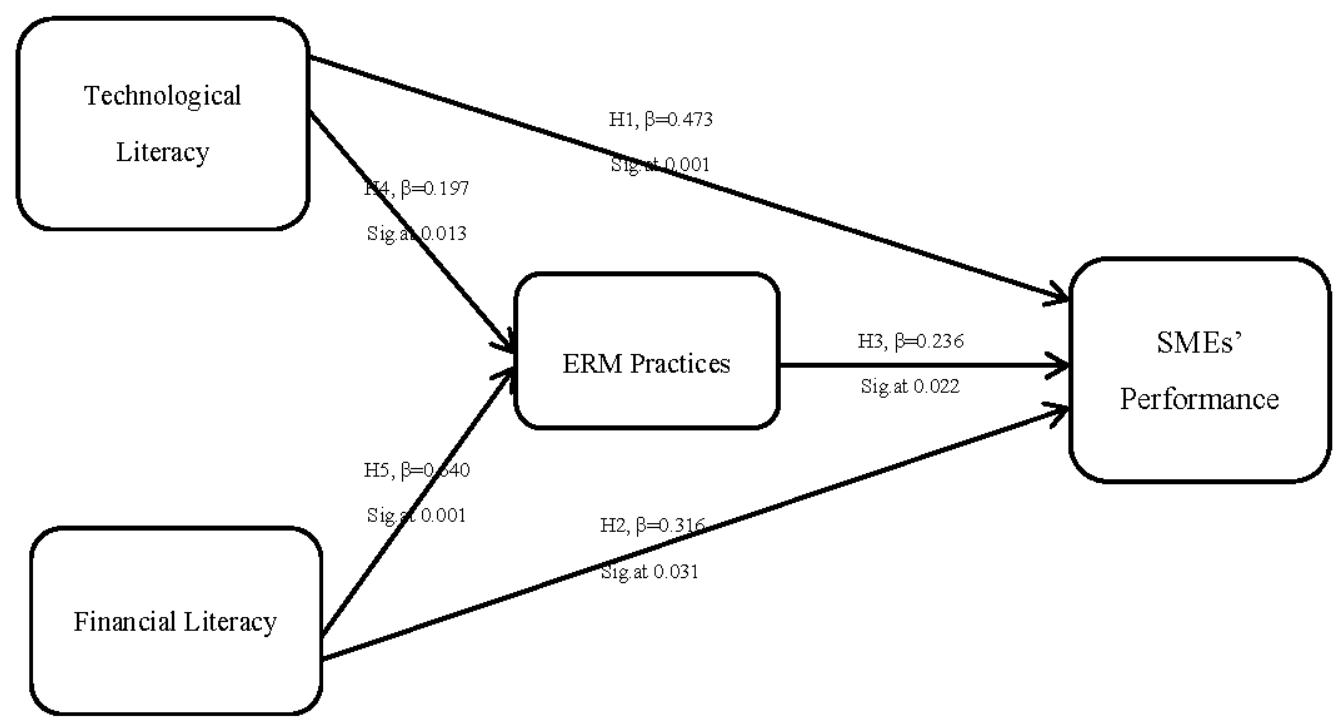

Figure 2. Direct path coefficients of structural model.

In this research, we tested five direct hypotheses. The results show that both technological literacy (TL; $\beta=0.473, p<0.001$ ) and financial literacy (FL; $\beta=0.316, p=0.031$ ) had a direct positive effect on SME performance. Thus, hypotheses 1 and 2 were accepted. Furthermore, ERM practices also had a significant direct effect on SME performance (FP; $\beta=0.236, p=0.022$ ), leading to $\mathrm{H} 3$ also being accepted. Hypotheses 4 and 6 of this study were developed to identify the direct effect of technological literacy and financial literacy on ERM practices. The results indicate that both technological literacy and financial literacy enabled improving the soundness of SME ERM practices, but the influence of financial literacy $(\beta=0.640, p<0.001)$ was higher than that of technological literacy $(\beta=0.197$, $p<0.001)$. Thus, hypotheses 4 and 6 were also accepted. 
The third phase was the evaluation of the coefficient of determination $\left(R^{2}\right)$ [93]. Accordingly, $R^{2}$ values of ERM practices (0.654) and SME performance (0.670) were above the threshold level of 0.50 , indicating a moderate predictive accuracy of the variables (Table 6) [94]. The fourth phase was to evaluate the effect of $f^{2}$ and, as per Table 6, four paths (TL-FP, FL-FP, ERM-FP, TL-ERM) had a medium effect, while FL-ERM had a higher effect.

Table 6. Direct path coefficients of the structural model.

\begin{tabular}{ccccccc}
\hline Path & Hypothesis & $\begin{array}{c}\text { Path } \\
\text { Coefficient }\end{array}$ & $\begin{array}{c}\boldsymbol{t} \text {-Value } \\
\mathbf{> 1 . 9 6}\end{array}$ & $\begin{array}{c}\boldsymbol{p} \text {-Value } \\
<\mathbf{0 . 0 5}\end{array}$ & $\boldsymbol{f}^{\mathbf{2}}$ & Significance \\
\hline $\mathrm{TL} \rightarrow \mathrm{FP}$ & 1 & 0.473 & 4.270 & 0.000 & 0.312 & Yes \\
$\mathrm{FL} \rightarrow \mathrm{FP}$ & 2 & 0.316 & 2.160 & 0.031 & 0.264 & Yes \\
$\mathrm{ERM} \rightarrow \mathrm{FP}$ & 3 & 0.236 & 2.966 & 0.022 & 0.212 & Yes \\
$\mathrm{TL} \rightarrow \mathrm{ERM}$ & 4 & 0.197 & 2.698 & 0.013 & 0.198 & Yes \\
$\mathrm{FL} \rightarrow \mathrm{ERM}$ & 6 & 0.640 & 5.270 & 0.000 & 0.473 & Yes \\
\hline
\end{tabular}

Significant at $5 \%$ for the two-tailed test $(>1.96)$.

The final phase of the structural model evaluation was the assessment of the predictive relevance $\left(Q^{2}\right)$ of the structural model. Accordingly, we followed the blindfolding procedure recommended by Hair Jr and Hult [90], and we used " $\mathrm{D}=7$ " as the omission distance in this study. As per Table 7, $Q^{2}$ values higher than zero for both endogenous constructs of the model provide evidence for the sufficient predictive relevance.

Table 7. Results of coefficient of determination $\left(R^{2}\right)$ and predictive relevance $\left(Q^{2}\right)$.

\begin{tabular}{ccc}
\hline Endogenous Latent Variable & $\boldsymbol{R}^{2}$ Value & $\boldsymbol{Q}^{2}$ Value \\
\hline ERM Practices & 0.654 & 0.361 \\
SME Performance & 0.670 & 0.376 \\
\hline
\end{tabular}

\subsection{ERM as a Mediator between Technological Literacy and SME Performance}

Hypothesis 5 assumes the mediation effect of ERM practices in the relationship between technological literacy and SME performance. The significance of the direct effects of technological literacy on SME performance was firstly checked using bootstrapping without the presence of the mediator in the model. The significant direct effect of technological literacy on SME performance confirmed the suitability of the data for further analysis. Then, the significance of the indirect effect and associated T-values was checked using the path coefficients when the mediator of ERM practices was included in the model. Smart-PLS does not calculate the indirect effect values automatically. As such, once the bootstrapping procedure (with a mediator) was completed, all 5000 path coefficients were copied to an Excel spreadsheet. Then, a column was created in the spreadsheet named "indirect effect", which was the multiplication result of the two paths "TL-ERM $\times$ ERM-FP". We used the "=STDEV ( )" Excel commend and calculated the standard deviation of those 5000 path coefficients, and the $t$-value of the indirect effect was calculated by dividing the indirect effect $(0.197 \times 0.236=0.0465)$ by the bootstrapping standard deviation $(0.0465 / 0.023=2.02)$. The result demonstrates the significance of the indirect effect. Then, we used the variance accounted for (VAF) value to assess the magnitude of the mediator. Accordingly, the VAF value was calculated as (indirect effect/total effect) $=0.0465 / 0.519$ $=0.0896$. This demonstrates that $8.96 \%$ of technological literacy's effect on SME performance can be explained via the ERM practices. Hair Jr and Hult [90] suggested that partial mediation exists when VAF is in the threshold level of $0.2-0.8$ and full mediation exists when it is higher than 0.8. Accordingly, ERM practices do not mediate the relationship between technological literacy and SME performance. Hence, hypothesis 5 was rejected. 


\subsection{ERM as a Mediator between Financial Literacy and SME Performance}

Hypothesis 7 assumes the mediation effect of ERM practices in the relationship between financial literacy and SME performance. After confirming the significant direct effect between FL and SME performance, the procedure explained in Section 4.3 was repeated and the VAF value was calculated in order to determine the magnitude of the mediating variable. The VAF value was calculated as (indirect effect $/$ total effect $)=0.151 / 0.467=0.323$. This demonstrates that $32.3 \%$ of financial literacy's effect on SME performance can be explained via the mediator of ERM practices. As per the Hair Jr and Hult [90], ERM practices partially mediate the relationship between financial literacy and SME performance. Hence, hypothesis 7 was partially supported. The results of the hypothesis testing are summarized in Table 8.

Table 8. Summary of hypothesis testing.

\begin{tabular}{lc}
\hline \multicolumn{1}{c}{ Hypotheses } & Decision \\
\hline H1: Technological literacy is positively related to SME performance & Accepted \\
\hline H2: Financial literacy is positively related to SME performance & Accepted \\
\hline H3: ERM practices has a positive effect on SME performance & Accepted \\
\hline H4: Technological literacy is positively related to ERM practices & Accepted \\
\hline $\begin{array}{l}\text { H5: ERM practices mediates the relationship between technological literacy } \\
\text { and SME performance }\end{array}$ & Rejected \\
\hline H6: Financial literacy has a positive effect on ERM practices & Accepted \\
\hline $\begin{array}{l}\text { H7: ERM practices mediates the relationship between financial literacy and } \\
\text { SME performance }\end{array}$ & Partially accepted \\
\hline
\end{tabular}

\section{Discussion}

\subsection{Discussion of the Findings}

The aim of our research was to investigate the role of techno-finance literacy in SME performance. We used PLS-SEM to investigate the direct and indirect (via ERM practices) effect of techno-finance literacy on SME performance. Furthermore, we examined the direct influence of technological literacy and financial literacy on ERM practices of the SMEs. The conceptual framework and the seven hypotheses developed with a thorough literature review were the foundation of this study. Questionnaire development, sample selection, data collection, and analysis were done using scientific methods. The results show that both technological literacy and financial literacy have a positive effect on SME performance and ERM practices. Furthermore, ERM practices were observed as having a partial mediation effect on the relationship between financial literacy and SME performance. ERM practices also positively influenced SME performance.

The positive effect of technological literacy on SME performance is congruent with the results of Ashrafi and Murtaza [41] and Iansiti and Lakhani [42], who revealed a positive impact of technological literacy on SME performance. We recognized technological literacy as one of the important components of a firm's knowledge resources and, therefore, our results agree with Carmeli and Tishler [53], who revealed a positive association between knowledge resources and SME performance. Furthermore, technological literacy helps SMEs to cope up with the rapid changes of this digitalized business environment. Accordingly, results of this research are consistent with the findings of Nelson [70], who proposed SMEs to adopt innovative mechanisms to boost their performance and facilitate navigating the digitalized business environment. Moreover, our results are in accordance with Bharadwaj [95], who revealed that technological literacy can influence organizational practices and, therefore, affect SME performance. Furthermore, findings of this study are congruent with Liang and You [96], who pointed out the prominence of technological literacy in enhancing the effectiveness of organizational communication, product design, and product development. However, it is challenging 
for SMEs in developing countries to introduce sophisticated technologies in their organizations due to many reasons. For instance, as explained by Fatoki [97] many SMEs do not have internet, an e-mail address, or a website. Therefore, it is apparent that weak technological literacy in developing countries undermines SME performance and is a threat to their survival. Our findings suggest the necessity of having technologically literate CFOs to improve the performance of SMEs.

The lack of financial literacy was observed to be a pertinent barrier to SME performance by past researchers. The absence of financial literacy restricts SME financial accessibility, as well as badly affects their decision-making process. Our study revealed a positive impact of financial literacy on SME performance, and it is in accordance with Eniola and Entebang [98], who found that financial literacy has a significant effect on SME performance. Furthermore, our results are congruent with those of Lusardi and Mitchell [54], who revealed the need for higher financial literacy to identify financial aspects of business decisions. Moreover, financial literacy allows SMEs to cope with economic transitions, thus enhancing their performance. Our findings are also consistent with Carbo-Valverde and Rodriguez-Fernandez [99], who pointed out the necessity of financial literacy to identify the most appropriate financial sources and to create a sound financial structure for the organization, which can improve performance. For instance, with higher financial literacy, SMEs can overcome the "equity gap" problem; hence, they can minimize interest expenses and collaterals when borrowing. As pointed out by Laitinen [100], higher financial literacy aids SMEs to prepare timely, accurate, and relevant financial reports which strengthen the decision-making process and performance of SMEs. Thus, the positive relationship between financial literacy and SME performance, which we found with this study, further confirms the results of previous studies. Our findings reported a positive relationship between ERM practices and SME performance, which is congruent with the findings of Zou and Hassan [67], who reported that ERM practices affect SME performances. Our results are also consistent with Agrawal [69], who showed that risk management practices positively influence SME performance. Soin and Collier [63] also observed that sound ERM practices enable SMEs to enhance their performance through the effective management of operational activities, assets, and information. Furthermore, our findings are also in accordance with Yilmaz and Flouris [61], who identified the importance of sound ERM practices to foresee the threats and opportunities that arise with global economic changes and to develop compressive long-term plans and strategies in order to ensure organizational performance. Moreover, Jalal-Karim [101] also reported the possibility of generating competitive advantages through sound ERM practices. However, Venkatraman and Fahd [102] reported the absence of sound ERM practices as the main barrier to SME performance. Weaker ERM practices are challenging for SMEs to effectively control their operations and, thus, threaten performance. Overall, the empirical evidence suggests that SMEs with sound ERM practices have a better chance of successfully dealing with the modern business environment. Thus, our results are congruent with the results of Jalal-Karim [101], who identified sound ERM practices as a competitive tool, which ensures SME performance.

In today's business environment, technological changes bring lots of opportunities while creating a considerable amount of risk for the SMEs. Thus, it is necessary to identify those risks and take precautionary actions to ensure SME performance. Our results revealed a positive relationship between technological literacy and ERM practices, supporting the fourth hypothesis (H4). Our findings uphold the results of Limsarun [71], who revealed a positive relationship between technological literacy and the performance of SMEs. Gutiérrez and Zuñiga [72] also pointed out the fact that technological literacy enables SMEs to develop and implement sophisticated ERM systems, which have an influence on the strategic decision-making and operations of organizations. Furthermore, our findings are also compatible with the findings of Arena and Arnaboldi [103], who found the significance of having higher technological literacy in establishing a sound internal control system for organizations. Moreover, as Kapurubandara and Lawson [74] mentioned, technological literacy influences organizational policies, which encourage SMEs to implement sound ERM practices.

The influence of financial literacy on ERM practices in the SME context received only limited attention; thus, in this study, we endeavored to fill that gap by exploring the effect of financial literacy 
on ERM practices. Our findings show a significant influence of financial literacy on SME ERM practices, thus supporting our sixth hypothesis (H6). Our outcome corroborates the results of Mabula and Ping [15], who posited that there is a positive relationship between financial literacy and ERM practices. Moreover, our findings are consistent with Smit and Watkins [76], who highlighted the need for higher financial literacy to implement efficient ERM systems for organizations. Moreover, Beheshti [77] also noted the necessity of financial literacy to link organizational strategies, policies, and procedures with the ERM system. Dionne and Triki [79] showed the significance of higher financial literacy of top-level executives in developing risk management practices. Their finding is also in accordance with ours, as, being a top-level executive, a CFO's financial literacy could influence the ERM practices of SMEs. Accordingly, higher financial literacy of SMEs enables them to strengthen their ERM practices, as it allows them to foresee the changes occurring in the business environment.

The mediating role of ERM practices in the relationship between financial literacy and SME performance is congruent with KBV [8]. According to KBV, higher financial literacy strengthens the explicit and tacit knowledge of organizations, which is useful in developing sound ERM practices for organizations [54]. This would facilitate SMEs to improve financial practices while minimizing the risks and costs, as well as strengthen SME performance. Our findings are also in line with Pierrakis and Collins [104], who showed the importance of financial literacy to introduce secured online money transfer systems and improve credit scores of the organizations. Our findings are also congruent with the findings of Dionne and Triki [79], who showed the necessity of having higher financial literacy in order to manage risks by adopting strong risk management practices. SMEs can expand their businesses if they can find new investors and financing strategies, as this allows them to overcome the financial accessibility problem. Thus, our findings are congruent with Pierrakis and Collins [104], as financial literacy enabled them to find new financial sources and investors, which also enhanced SME performance. Financial literacy empowers top managers to implement new security and internal control systems in their organizations, thereby enhancing SME performance by avoiding fraud and errors. All in all, financial literacy influences SME performance via ERM practices. Our findings are in accordance with Eniola and Entebang [105], who pointed out the possibility of financial literacy in enhancing organizational performance and providing competitive advantages. Our findings are also consistent with Bansal [106], who noted that financial literacy enables SMEs to collect, evaluate, interpret, and share relevant and timely information efficiently and effectively, thereby improving SME performance. Accordingly, sound ERM practices are necessary for SMEs, as they directly and indirectly influence SME performance. Thus, our study extends the knowledge on techno-finance literacy and ERM practices by assessing new mechanisms that can augment the performance of the SMEs.

\subsection{Theoretical Implications}

This study emphasized the significance of techno-finance literacy and ERM practices in SME performance. Furthermore, higher techno-finance literacy leads to sound ERM practices for SMEs. This denotes the significance of using different theories and concepts to explain the power of knowledge resources such as techno-finance literacy in SME performance. Moreover, investigating the effect of ERM practices on SME performance also expands the understanding on ERM practices in the SME context.

This research filled a contextualized gap by identifying determinants of SME performance in the Sri Lankan context, a developing economy in south Asia. Furthermore, the steadiness of our results with those of previous researches conducted in developed and developing countries denotes that techno-finance literacy and ERM practices are universal concepts rather than context-specific concepts. Thus, this signifies the necessity of higher techno-finance literacy and sound ERM practices for the development of the global SME sector.

The use of PLS-SEM to study the role of techno-finance literacy in SME performance also filled a methodological gap, thus contributing to the literature. Most previous studies only explored the direct effect of techno-finance literacy on SME performance, leaving a knowledge gap on the 
prospective indirect effects of techno-finance literacy on SME performance. We endeavored to fill this gap by introducing ERM practices as a mediating variable in our structural equation model and then tested hypotheses on indirect relationships. Furthermore, in our study, we combined two knowledge resources, namely, techno-finance literacy via ERM practices, which also adds a novel contribution to the literature on SME performance. The identified partial mediation of ERM practices hints at the presence of additional mechanisms linking financial literacy and the performance of SMEs.

\subsection{Implications for Managers}

The significance of techno-finance literacy in the context of SME performance is two-fold. Firstly, techno-finance literacy directly influences SME performance. Secondly, techno-finance literacy directly influences ERM practices and, in turn, indirectly influences SME performance. Accordingly, possible managerial implications are discussed below, in order to ensure SME performance.

From the managerial perspective, regular training programs and seminars should be arranged to improve the knowledge on techno-finance literacy of the SMEs. Special attention is required in order to enhance the technological literacy of the accounting and finance staff of the SMEs, as this is helpful to implement sound ERM practices. Furthermore, considerable investment is needed to introduce new technology for SMEs, as this is vital to expand the SME's target markets. However, SMEs are required to recruit well-qualified information technology (IT) specialists to enhance the technological literacy of their organizations. Moreover, without compromising on the IT and accounting staff of the organization, basic financial and technological training should also be given to other staff of the organization. When recruiting CFOs, SMEs should assess their technological knowledge on the basis of their accounting qualifications. Techno-finance-literate CFOs would have a greater chance of introducing sound ERM practices in the SMEs. Moreover, SMEs should gradually introduce more computerized work than paperwork in their organizations, as this would increase the operational efficiency and strengthen the internal control systems of the organizations. The top managers should also enhance their techno-finance literacy, as it empowers them to think "out of the box" when developing organizational strategies, policies, and procedures.

In this study, ERM practices were identified as an important determinant of SME performance. Top-level managers should consult both IT and finance specialists while developing ERM practices for their organizations. Furthermore, managers should recognize the competitive advantages gained through ERM practices, as these affect SME performance. Moreover, SMEs should endeavor to use technological approaches to identify and manage organizational risks. In other words, rather than manual ERM practices, computerized ERM practices would enhance SME performance. Given the importance of financial literacy to implement sound ERM practices, we recommend SMEs to organize more ERM-related programs for managers who are directly involved in the organizational decision-making process.

The contribution of other stakeholders like policymakers is also very important in the performance of SMEs in developing economies. Policymakers can organize seminars and training programs to enrich an SME's techno-finance knowledge, as well as enhance the understanding of how new business opportunities arise in this digitalized business environment. Furthermore, policies can be introduced to encourage SMEs to transform their business into a digital business. For instance, governments can introduce new tax concessionaries and financial facilities for SMEs who introduce new technologies for their organizations. Government officers, specialized in IT, can be appointed to assist SMEs with digitalizing their organizations. Other third parties such as bankers can also motivate SMEs to use new technologies with their transactions. Moreover, policies introduced to ensure the security of paperless transactions would also help to save both time and cost of the business community. For instance, trust in Quick Response (QR) code systems would simplify business transactions. Furthermore, organizations such as central banks can introduce new secured financial-trade platforms by linking SMEs, bankers, and suppliers. This would assist SMEs to enhance their techno-finance literacy. 


\subsection{Limitations and Future Research Directions}

Even though this research adds novel contributions to the fields of techno-finance literacy, ERM practices, and SME performance, it has a few limitations. Firstly, the sample of this research was collected only from three provinces of Sri Lanka. In future studies, the size of the sample can be further extended to provide a more comprehensive picture on the techno-finance literacy of Sri Lankan SMEs. Furthermore, the model used in this study can be tested in the context of other developing nations, which will help in generalizing the results of our research. Secondly, the cross-sectional design of this study is another limitation, as it prevented us from investigating causal relationships among the variables. Thus, future researchers can investigate the cause-and-effect relationships among these variables with a longitudinal study. Thirdly, in this research, we used a single-mediator structural equation model and, thus, we recommend future researchers to introduce multiple mediators such as entrepreneurial competencies to expand the model. The identified partial mediation of ERM practices in the relationship between financial literacy and SME performance indicates the presence of new pathways to strengthen this relationship. Thus, more precursors to the model to identify new antecedents of SME performance can be introduced in future studies.

\section{Conclusions}

Research on the influence of knowledge resources on SME performance can be identified as a growing research area. This research endeavored to examine the influence of techno-finance literacy on SME performance. Accordingly, we developed a single-mediator structural model to investigate the direct and indirect (via ERM practices) impacts of techno-finance literacy on SME performance. The knowledge-based view provided the necessary theoretical background for this study. The data comprised 319 CFOs working in SMEs in Sri Lanka. For this purpose, we employed a structured questionnaire and used both SPSS 23 and Smart-PLS software to get results from our preliminary analysis and to test the hypotheses of this study. The findings underscore that both technological literacy and financial literacy have a direct and positive impact on ERM practices and SME performance, while ERM practices partially mediate the relationship between financial literacy and SME performance. Furthermore, ERM practices are also recognized as a vital antecedent of SME performance. Therefore, we conclude that both technological and financial literacy are imperative predictors of the soundness of ERM practices and SME performance. Moreover, technological literacy had a higher direct influence on SME performance than other variables. This denotes the necessity of transforming SMEs into digitalized organizations in order to enhance their performance. Furthermore, this study expanded the literature on SME performance by introducing ERM practices as an antecedent of SME performance and proposed new pathways to enhance SME performance, especially in developing economies.

Author Contributions: K.M.M.C.B.K. collected data, performed the data analysis, and wrote the first draft of the paper; K.M.M.C.B.K., J.Y., S.S., and P.R.W. conceptualized and designed the study, substantially revised the manuscript, and finalized the paper. All authors read and agreed to the published version of the manuscript.

Funding: This research received no external funding.

Conflicts of Interest: The authors declare no conflicts of interest.

\section{References}

1. Agyei, S.K.; Nsiah, C. Culture, financial literacy, and SME performance in Ghana. Cogent Econ. Financ. 2018, 6, 1463813. [CrossRef]

2. Aremu, M.A.; Adeyemi, S.L. Small and medium scale enterprises as a survival strategy for employment generation in Nigeria. J. Sustain. Dev. 2011, 4, 200.

3. Smallbone, D. Government and entrepreneurship in transition economies: the case of small firms in business services in Ukraine. Strat. Dir. 2010, 26, 655-670. [CrossRef]

4. Jianmu, Y.; Kulathunga, K. How Does Financial Literacy Promote Sustainability in SMEs? A Developing Country Perspective. Sustainability 2019, 11, 2990. [CrossRef] 
5. Omiunu, O.G. E-literacy-adoption model and performance of women-owned SMEs in Southwestern Nigeria. J. Glob. Entrep. Res. 2019, 9, 26. [CrossRef]

6. Oláh, J.; Kovács, S.; Virglerova, Z.; Lakner, Z.; Kovacova, M.; Popp, J. Analysis and Comparison of Economic and Financial Risk Sources in SMEs of the Visegrad Group and Serbia. Sustainability 2019, 11, 1853. [CrossRef]

7. $\mathrm{Wu}, \mathrm{J} . ; \mathrm{Si}, \mathrm{S}$. Poverty reduction through entrepreneurship: incentives, social networks, and sustainability. Asian Bus. Manag. 2018, 17, 243-259. [CrossRef]

8. Grant, R.M. Toward a knowledge-based theory of the firm. Strat. Manag. J. 1996, 17, 109-122. [CrossRef]

9. Hussain, J.; Salia, S.; Karimu, A. Is knowledge that powerful? Financial literacy and access to finance. J. Small Bus. Enterp. Dev. 2018, 25, 985-1003. [CrossRef]

10. FFlorio, C.; Leoni, G. Enterprise risk management and firm performance: The Italian case. Br. Account. Rev. 2017, 49, 56-74. [CrossRef]

11. Yang, Y.; Chen, X.; Gu, J.; Fujita, H. Alleviating Financing Constraints of SMEs through Supply Chain. Sustainability 2019, 11, 673. [CrossRef]

12. Ying, Q.; Hassan, H.; Ahmad, H. The Role of a Manager's Intangible Capabilities in Resource Acquisition and Sustainable Competitive Performance. Sustainability 2019, 11, 527. [CrossRef]

13. Songling, Y.; Ishtiaq, M.; Ahmad, H.; Yang, S. Enterprise Risk Management Practices and Firm Performance, the Mediating Role of Competitive Advantage and the Moderating Role of Financial Literacy. J. Risk Financ. Manag. 2018, 11, 35. [CrossRef]

14. Hobijn, B.; Jovanovic, B. The Information-Technology Revolution and the Stock Market: Evidence. Am. Econ. Rev. 2001, 91, 1203-1220. [CrossRef]

15. Mabula, J.B.; Dong, H. Use of Technology and Financial Literacy on SMEs Practices and Performance in Developing Economies. Int. J. Adv. Comput. Sci. Appl. 2018, 9, 74-82. [CrossRef]

16. Mehrtens, J.; Cragg, P.B.; Mills, A.M. A model of Internet adoption by SMEs. Inf. Manag. 2001, 39, 165-176. [CrossRef]

17. Van Akkeren, J.; Harker, D. Mobile data technologies and small business adoption and diffusion: An empirical study of barriers and facilitators. In Mobile Commerce: Technology, Theory and Applications; IGI Global: Hershey, PA, USA, 2003; pp. 218-244.

18. Hashim, J. Information communication technology (ICT) adoption among SME owners in Malaysia. Int. J. Bus. Inf. 2007, 2, 221-240.

19. Osano, H.M. Factors Influencing Global Expansion/Scalability of Small and Medium Enterprises: A Kenyan Case. World Technopolis Rev. 2019, 8, 21-42.

20. Glavas, C.; Mathews, S.; Russell-Bennett, R. Knowledge acquisition via internet-enabled platforms. Int. Mark. Rev. 2019, 36, 74-107. [CrossRef]

21. Bowen, M.M.; Johnson, K.R. Entrepreneurial Skills for the 21st Century Workplace: The SME Sector. In Handbook of Research on Promoting Higher-Order Skills and Global Competencies in Life and Work; IGI Global: Hershey, PA, USA, 2019; pp. 56-69.

22. Barney, J. Firm Resources and Sustained Competitive Advantage. J. Manag. 1991, 17, 99-120. [CrossRef]

23. Wernerfelt, B. A resource-based view of the firm. Strat. Manag. J. 1984, 5, 171-180. [CrossRef]

24. Kor, Y.Y.; Mahoney, J.T.; Michael, S.C. Resources, Capabilities and Entrepreneurial Perceptions. J. Manag. Stud. 2007, 44, 1187-1212. [CrossRef]

25. Lei, D.; Hitt, M.A.; Bettis, R. Dynamic core competences through meta-learning and strategic context. J. Manag. 1996, 22, 549-569. [CrossRef]

26. Theriou, N.; Aggelidis, V.; Theriou, G. The Mediating Effect of the Knowledge Management Process to the Firm's Performance: A Resource-Based View. Int. J. Econ. Bus. Adm. 2014, 2, 87-114. [CrossRef]

27. Hedlund, G. A model of knowledge management and the N-form corporation. Strat. Manag. J. 2007, 15, 73-90. [CrossRef]

28. Zack, M.H. Developing a Knowledge Strategy. Calif. Manag. Rev. 1999, 41, 125-145. [CrossRef]

29. Curado, C.; Henriques, P.L.; Bontis, N. Intellectual capital disclosure payback. Manag. Decis. 2011, 49, 1080-1098. [CrossRef]

30. Kubr, M. Management Consulting: A Guide to the Profession; International Labour Organization: Geneva, Switzerland, 2002.

31. Jappelli, T.; Padula, M. Investment in financial literacy and saving decisions. J. Bank. Financ. 2013, 37, 2779-2792. [CrossRef] 
32. Lusardi, A.; Mitchell, O.S. Financial literacy around the world: An overview. J. Pension Econ. Financ. 2011, 10, 497-508. [CrossRef]

33. Bontis, N.; Keow, W.C.C.; Richardson, S. Intellectual capital and business performance in Malaysian industries. J. Intellect. Cap. 2000, 1, 85-100. [CrossRef]

34. Omiunu, O.G. Deploying ICT to Enhance Small Businesses and Achieving Sustainable Development: A Paradigm to Reducing Poverty and Unemployment and Enhancing a Sustainable National Development in Nigeria. In Handbook of Research on Small and Medium Enterprises in Developing Countries; IGI Global: Hershey, PA, USA, 2017; pp. 208-232.

35. Ajiferuke, I.; Olatokun, W. Sectoral analysis of ICT use in Nigeria. In Encyclopedia of Information Science and Technology, 2nd ed.; IGI Global: Hershey, PA, USA, 2009; pp. 3364-3368.

36. Ifijeh, G.; Iwu-James, J.; Adebayo, O. Digital Inclusion and Sustainable Development in Nigeria: The Role of Libraries. In Proceedings of the 3rd International Conference on African Development Issues, Ota, Nigeria, 9-11 May 2016.

37. Zhang, X.; Majid, S.; Foo, S. The Role of Information Literacy in Environmental Scanning as a Strategic Information System-A Study of Singapore SMEs. In International Symposium on Information Management in a Changing World; Springer: Berlin/Heidelberg, Germany, 2010.

38. Rhodes, J. Can E-commerce enable marketing in an African rural women's community based development organisation? Inf. Sci. 2003, 6, 157-172.

39. Ladokun, I.; Osunwole, O.; Olaoye, B. Information and Communication Technology in Small and Medium Enterprises: Factors affecting the Adoption and use of ICT in Nigeria. Int. J. Acad. Res. Econ. Manag. Sci. 2013, 2, 74. [CrossRef]

40. Sajuyigbe, A.; Alabi, E. Impact of information and communication technology in selected small and medium enterprises in Osogbo metropolis, Nigeria. J. Sch. Commun. Inf. Technol. 2012, 3, 24-35.

41. Ashrafi, R.; Murtaza, M. Use and impact of ICT on SMEs in Oman. Electron. J. Inf. Syst. Eval. 2008, 11, 125-138.

42. Iansiti, M.; Lakhani, K.R. Digital Ubiquity: How Connections, Sensors, and Data Are Revolutionizing Business. Harv. Bus. Rev. 2014, 92, 91-99.

43. Windrum, P.; de Berranger, P. The Adoption of e-Business Technology by SMEs; Jones, O., Tilley, F., Eds.; John Wiley \& Sons: Cheltenham, UK, 2002; pp. 177-201.

44. Simpson, M.; Docherty, A.J. E-commerce adoption support and advice for UK SMEs. J. Small Bus. Enterp. Dev. 2004, 11, 315-328. [CrossRef]

45. Fink, D. Guidelines for the Successful Adoption of Information Technology in Small and Medium Enterprises. Int. J. Inf. Manag. 1998, 18, 243-253. [CrossRef]

46. Zaied, A.N.H. Barriers to E-Commerce Adoption in Egyptian SMEs. Int. J. Inf. Eng. Electron. Bus. 2012, 4, 9-18. [CrossRef]

47. Estrin, L.; Foreman, J.T.; Garcia, S. Overcoming Barriers to Technology Adoption in Small Manufacturing Enterprises (SMEs); Carnegie-Mellon Software Engineering Inst: Pittsburgh, PA, USA, 2003.

48. Irjayanti, M.; Azis, A.M. Barrier Factors and Potential Solutions for Indonesian SMEs. Procedia Econ. Financ. 2012, 4, 3-12. [CrossRef]

49. Eniola, A.A.; Entebang, H. SME Firm Performance-Financial Innovation and Challenges. Procedia Soc. Behav. Sci. 2015, 195, 334-342. [CrossRef]

50. Ong, J.-W.; Ismail, H.B. Sustainable competitive advantage through information technology competence: Resource-based view on small and medium enterprises. Commun. IBIMA 2008, 1, 62-70.

51. Das, T.K.; Teng, B.-S. A resource-based theory of strategic alliances. J. Manag. 2000, 26, 31-61. [CrossRef]

52. Conner, K.R.; Prahalad, C.K. A Resource-Based Theory of the Firm: Knowledge Versus Opportunism. Organ. Sci. 1996, 7, 477-501. [CrossRef]

53. Carmeli, A.; Tishler, A. The relationships between intangible organizational elements and organizational performance. Strateg. Manag. J. 2004, 25, 1257-1278. [CrossRef]

54. Lusardi, A.; Mitchell, O.S. The Economic Importance of Financial Literacy: Theory and Evidence. J. Econ. Lit. 2014, 52, 5-44. [CrossRef]

55. Huston, S. Measuring Financial Literacy. J. Consum. Aff. 2010, 44, 296-316. [CrossRef]

56. Wise, S. The Impact of Financial Literacy on New Venture Survival. Int. J. Bus. Manag. 2013, 8, 30. [CrossRef] 
57. Widdowson, D.; Hailwood, K. Financial literacy and its role in promoting a sound financial system. Reserve Bank New Zealand Bull. 2007, 70, 37-49.

58. Davidson, W.N.; Xie, B.; Xu, W. Market reaction to voluntary announcements of audit committee appointments: The effect of financial expertise. J. Account. Public Policy 2004, 23, 279-293. [CrossRef]

59. Behrman, J.R.; Mitchell, O.S.; Soo, C.K.; Bravo, D. How Financial Literacy Affects Household Wealth Accumulation. Am. Econ. Rev. 2012, 102, 300-304. [CrossRef]

60. Allgood, S.; Walstad, W.B. The effects of perceived and actual financial literacy on financial behaviors. Econ. Inq. 2016, 54, 675-697. [CrossRef]

61. Yilmaz, A.K.; Flouris, T. Enterprise risk management in terms of organizational culture and its leadership and strategic management. In Corporate Risk Management for International Business; Springer: Berlin/Heidelberg, Germany, 2017; pp. 65-112.

62. Ittner, C.D.; Oyon, D. Risk Ownership, ERM Practices, and the Role of the Finance Function. J. Manag. Account. Res. 2019. [CrossRef]

63. Soin, K.; Collier, P. Risk and risk management in management accounting and control. Manag. Account. Res. 2013, 24, 82-87. [CrossRef]

64. Lechner, P.; Gatzert, N. Determinants and value of enterprise risk management: Empirical evidence from Germany. Eur. J. Financ. 2018, 24, 867-887. [CrossRef]

65. Elahi, E. Risk management: The next source of competitive advantage. Foresight 2013, 15, 117-131. [CrossRef]

66. Callahan, C.; Soileau, J. Does enterprise risk management enhance operating performance? Adv. Account. 2017, 37, 122-139. [CrossRef]

67. Zou, X.; Hassan, C.H. Enterprise risk management in China: The impacts on organisational performance. Int. J. Econ. Policy Emerg. Econ. 2017, 10, 226. [CrossRef]

68. Lajili, K. Corporate Risk Disclosure and Corporate Governance. J. Risk Financ. Manag. 2009, 2, $94-117$. [CrossRef]

69. Agrawal, R. 'Enterprise risk management' essential for survival and sustainable development of micro, small and medium enterprises. Int. Rev. 2016, 2016, 117-124. [CrossRef]

70. Nelson, R.R. An Evolutionary Theory of Economic Change; Harvard University Press: Cambridge, MA, USA, 2009.

71. Limsarun, T. The Sustainability of Small and Medium-sized Enterprises (SMEs) in A Digital Economy Era. J. Bus. Adm. 2015, 4, 113-124.

72. Gutiérrez, R.T.; Zuñiga, X.; Tomé, E.; Magaña, X.; Ostolaza, I. The benefits of Digital Best Practices Program: Improving digital literacy in SMEs of Basque tourism industry. Improv. Sustain. Tour. XXIst Century 2016, $57,99$.

73. Ramsey, E.; Ibbotson, P.; McCole, P. Factors that impact technology innovation adoption among irish professional service sector smes. Int. J. Innov. Manag. 2008, 12, 629-654. [CrossRef]

74. Kapurubandara, M.; Lawson, R. SMEs in developing countries need support to address the challenges of adopting e-commerce technologies. In Proceedings of the Bled eConference, Bled, Slovenia, 3-6 June 2007; p. 24.

75. Meidell, A.; Kaarbøe, K. How the enterprise risk management function influences decision-making in the organization - A field study of a large, global oil and gas company. Br. Account. Rev. 2017, 49, 39-55. [CrossRef]

76. Smit, Y. A literature review of small and medium enterprises (SME) risk management practices in South Africa. Afr. J. Bus. Manag. 2012, 6, 6324. [CrossRef]

77. Beheshti, H.M. What managers should know about ERP/ERP II. Manag. Res. News 2006, 29, $184-193$. [CrossRef]

78. Shanahan, P.; McParlane, J. Serendipity or strategy? An investigation into entrepreneurial transnational higher education and risk management. Horizon 2005, 13, 220-228. [CrossRef]

79. Dionne, G.; Triki, T. Risk Management and Corporate Governance: The Importance of Independence and Financial Knowledge for the Board and the Audit Committee; HEC Montreal: Montréal, QC, Canada, 2005.

80. Hommel, U.; King, R. The emergence of risk-based regulation in higher education. J. Manag. Dev. 2013, 32, 537-547. [CrossRef]

81. Robson, C.; McCartan, K. Real World Research; John Wiley \& Sons: Hoboken, NJ, USA, 2016.

82. Burns, A.; Bush, R. Marketing Research, 5th ed.; John Wiley \& Sons: Hoboken, NJ, USA, 2006. 
83. Pham, Q.T. Measuring the ICT maturity of SMEs. J. Knowl. Manag. Pract. 2010, 11, 1-14.

84. Bongomin, G.O.C.; Munene, J.C.; Ntayi, J.M.; Malinga, C.A.; Okello, G.C.B. Exploring the mediating role of social capital in the relationship between financial intermediation and financial inclusion in rural Uganda. Int. J. Soc. Econ. 2018, 45, 829-847. [CrossRef]

85. Sax, J.; Torp, S. Speak up! Enhancing risk performance with enterprise risk management, leadership style and employee voice. Manag. Decis. 2015, 53, 1452-1468. [CrossRef]

86. Anwar, M. business model innovation and smes performance-does competitive advantage mediate? Int. J. Innov. Manag. 2018, 22, 1850057. [CrossRef]

87. Runyan, R.C.; Dröge, C.; Swinney, J. Entrepreneurial Orientation versus Small Business Orientation: What Are Their Relationships to Firm Performance? J. Small Bus. Manag. 2008, 46, 567-588. [CrossRef]

88. Haber, S.; Reichel, A. Identifying Performance Measures of Small Ventures-The Case of the Tourism Industry. J. Small Bus. Manag. 2005, 43, 257-286. [CrossRef]

89. Ma, D.; Ullah, F.; Khattak, M.S.; Ahmad, H. Do International Capabilities and Resources Configure Firm's Sustainable Competitive Performance? Research within Pakistani SMEs. Sustainability 2018, 10, 4298. [CrossRef]

90. Leguina, A. A primer on partial least squares structural equation modeling (PLS-SEM). Int. J. Res. Method Educ. 2015, 38, 220-221. [CrossRef]

91. Fornell, C.; Larcker, D.F. Evaluating structural equation models with unobservable variables and measurement error. J. Mark. Res. 1981, 18, 39-50. [CrossRef]

92. Henseler, J.; Ringle, C.M.; Sarstedt, M. A new criterion for assessing discriminant validity in variance-based structural equation modeling. J. Acad. Mark. Sci. 2014, 43, 115-135. [CrossRef]

93. Wong, K.Y.; Aspinwall, E. An empirical study of the important factors for knowledge-management adoption in the SME sector. J. Knowl. Manag. 2005, 9, 64-82. [CrossRef]

94. Hair, J.F.; Anderson, R.E.; Babin, B.J.; Black, W.C. Multivariate Data Analysis: A Global Perspective; Pearson: Upper Saddle River, NJ, USA, 2006.

95. Bharadwaj, A.S. A Resource-Based Perspective on Information Technology Capability and Firm Performance: An Empirical Investigation. MIS Q. 2000, 24, 169. [CrossRef]

96. Liang, T.; You, J.; Liu, C. A resource-based perspective on information technology and firm performance: A meta analysis. Ind. Manag. Data Syst. 2010, 110, 1138-1158. [CrossRef]

97. Fatoki, O. The Financial Literacy of Micro Entrepreneurs in South Africa. J. Soc. Sci. 2014, 40, 151-158. [CrossRef]

98. Eniola, A.A.; Entebang, H.; Sakariyau, O.B. Small and medium scale business performance in Nigeria: Challenges faced from an intellectual capital perspective. Int. J. Res. Stud. Manag. 2015, 4, 59-71. [CrossRef]

99. Carbo-Valverde, S.; Fernandez, F.R.; Udell, G.F. Trade Credit, the Financial Crisis, and SME Access to Finance. J. Money, Crédit. Bank. 2016, 48, 113-143. [CrossRef]

100. Laitinen, E.K. Prediction of failure of a newly founded firm. J. Bus. Ventur. 1992, 7, 323-340. [CrossRef]

101. Jalal-Karim, A. Leveraging enterprise risk management (ERM) for boosting competitive business advantages in Bahrain. World J. Entrep. Manag. Sustain. Dev. 2013, 9, 65-75. [CrossRef]

102. Venkatraman, S.; Fahd, K. Challenges and Success Factors of ERP Systems in Australian SMEs. Systems 2016, 4, 20. [CrossRef]

103. Arena, M.; Arnaboldi, M.; Azzone, G. Is enterprise risk management real? J. Risk Res. 2011, 14, $779-797$. [CrossRef]

104. Pierrakis, Y.; Collins, L. Crowdfunding: A New Innovative Model of Providing Funding to Projects and Businesses. SSRN Electron. J. 2013. [CrossRef]

105. Eniola, A.A.; Entebang, H. SME Managers and Financial Literacy. Glob. Bus. Rev. 2017, 18, 559-576. [CrossRef]

106. Bansal, S. Perspective of Technology in Achieving Financial Inclusion in Rural India. Procedia Econ. Financ. 2014, 11, 472-480. [CrossRef]

(C) 2020 by the authors. Licensee MDPI, Basel, Switzerland. This article is an open access article distributed under the terms and conditions of the Creative Commons Attribution (CC BY) license (http://creativecommons.org/licenses/by/4.0/). 